\title{
EDITORIAL
}

\section{Algunas preocupaciones acerca de la educación universitaria en el Perú}

Desde hace mucho tiempo en el Perú existen universidades públicas y privadas según fueran respectivamente, financiadas por el Estado o por particulares interesados en la educación universitaria. En ambos casos, seleccionaban a los postulantes más idóneos para formar con mucho esfuerzo recursos humanos profesionales capacitados para realizar investigación científica y con espíritu de servicio a la comunidad, por otro lado no se esperaba que existieran universidades con intereses puramente económicos.

Con la dación del Decreto Legislativo 882, a fines del año 2006, se permite que personas o instituciones particulares, mediante inversión con enfoque netamente empresarial, incursionen en la creación, promoción, conducción, adquisición o transferencia, de universidades para funcionar según los fines de una empresa de libre mercado. En estos casos el éxito para los inversionistas se mide en términos de producción económica aunque para ello se recurra a medios y mecanismos que permitan lograr un lucro, en muchos casos, más allá de la justa retribución por la inversión hecha.

Esta situación no contribuye a mejorar la formación del potencial humano que el país requiere, en términos de calidad, cantidad y carreras ofrecidas. Por otro lado distorsionan el interés de los candidatos al ofrecerles carreras cuyo prestigio "proviene de épocas anteriores" y que ahora se encuentran superpobladas con profesionales de calidad heterogénea, que no logran insertarse plenamente en el mercado laboral y no logran contribuir con el desarrollo del país, el bienestar de la población y su propia realización. A ello se debe sumar el alto costo de los estudios que limitan las oportunidades de muchos aspirantes intelectualmente capacitados.

Esta situación ha conllevado a que las universidades públicas y particulares sin fines de lucro se vean obligadas a competir académicamente entre ellas y con las universidades-empresa, en un terreno que no es propio del quehacer universitario, como por ejemplo la captación de postulantes por diversos medios. En esta competencia muchas de las universidades-empresa tienen ventajas desleales y no vacilan en colonizar el ámbito educativo universitario con actores e intereses alejados de la verdadera tarea académica que como institución superior le compete. De esta forma las universidades públicas y particulares sin fines de lucro cada día están siendo empujadas a su casi extinción, por factores ajenos a los altos fines de la vida universitaria.

Aún cuando hay casos de universidades privadas que logran conservar excelencia y calidad en la tarea académica, existe en general un panorama preocupante para el país, inconveniente para el desarrollo de la genuina labor académica universitaria y distante de la satisfacción de las necesidades de la población, que hace necesario reflexionar acerca de la urgencia de una nueva legislación universitaria que, corrigiendo la normatividad actual, promueva en cada institución de educación superior el cumplimiento de una verdadera formación profesional, que estimule el desarrollo de la investigación científica y comprometa a los estudiantes en actividades que beneficien a la comunidad, logrando de esta manera una excelencia en la educación, en donde los costos de la enseñanza deben ser apropiados, factibles y compatibles con la real situación social y económica del estudiante peruano.

Esta tarea si bien no será fácil, consideramos perentoria y que debe ser asumida por los académicos más representativos de cada universidad cuyos fines no sean de lucro.

Dr. Juan Bernal Morales

Past Decano

Facultad de Estomatología 